\title{
Efektivitas Iklan Layanan Masyarakat "Adaptasi Kebiasaan Baru Cegah Covid-19 di Fasilitas Olahraga" dalam Media YouTube
}

\author{
Fujimori $^{1}$, Gregorius Genep Sukendro ${ }^{2 *}$ \\ ${ }^{1}$ Fakultas Ilmu Komunikasi, Universitas Tarumanagara, Jakarta \\ Email: fujimori.915180263@stu.untar.ac.id \\ ${ }^{2}$ Fakultas Ilmu Komunikasi, Universitas Tarumanagara, Jakarta* \\ Email: geneps@fikom.untar.ac.id
}

Masuk tanggal : 15-12-2021 revisi tanggal : 06-01-2022, diterima untuk diterbitkan tanggal : 16-01-2022

\begin{abstract}
This research has a purpose for measuring the level of effectiveness of public service ads 'Adaptation to New habits Prevent Covid-19 in the Sports Facilities' on media youtube. Public service advertising is created and displayed dikanal Youtube Directorate of Health Promotion and Community Empowerment Ministry of Health of the Republic of Indonesia of 'Public Service Ads Adaptation to New Habits Prevent Covid-19 in the Sports Facilities' until now it has been watched more than 20 thousand spectators. This quantitative research has an aim of observing the current behavior and consists of one variable (univariate) using the EPIC Model theory to measure the effectiveness of advertising. Researchers collected data by distributing 100 questionnaires to respondents aged 15 years and over, using YouTube and domiciled on the island of Java. Data was collected to measure the 4 dimensions of the EPIC Model, namely Empathy, Persuasion, Impact, and Communication. After calculating the average score, the empathy dimension got an epic rate of 4, persuasion 3.9, impact 3.88, and communication 4.16. This result state that the public service advertisement "Adaptation of New Habits to Prevent Covid-19 in Sports Facilities" on YouTube is in the effective category.
\end{abstract}

Keywords: effectivity, epic model, public service announcement

\begin{abstract}
Abstrak
Penelitian ini memiliki tujuan buat mengukur taraf efektivitas iklan layanan masyarakat 'Adaptasi kebiasaan Baru Cegah Covid-19 di Fasilitas Olahraga' pada media youtube. Iklan layanan masyarakat yang dibuat dan ditampilkan dikanal Youtube Direktorat Promosi Kesehatan dan Pemberdayaan Masyarakat Kementrian Kesehatan Republik Indonesia berjudul 'Iklan Layanan Masyarakat Adaptasi Kebiasaan Baru Cegah Covid-19 di Fasilitas Olahraga' hingga saat ini telah ditonton lebih dari 20 ribu penonton.Penelitian ini merupakan penelitian kuantitatif dengan tujuan mengamati perilaku yg sedang terjadi serta terdiri dari satu variabel (univariat) menggunakan teori EPIC contoh buat mengukur efektivitas iklan. Peneliti mengumpulkan data dengan cara berbagi 100 kuisioner kepada responden yang berumur 15 tahun keatas ,memakai youtube dan berdomisili pada pulau Jawa. Data dikumpulkan untuk mengukur dimensi dmensi EPIC contoh yang meliputi dimensi ikut merasakan, Persuasi, Impact, dan Komunikasi. setelah dilakukan perhitungan skor rata rata, dimensi ikut merasakan mendapatkan epic rate sebanyak 4, persuasion 3,9, impact 3,88, dan communication 4,16. sesuai hasil tersebut bisa dikatakan bahwa iklan'Adaptasi kebiasaan Baru Cegah Covid-19 di fasilitas Olahraga' dalam youtube masuk pada kategori efektif.
\end{abstract}

Kata Kunci: efektivitas, epic model, iklan layanan masyarakat 


\section{Pendahuluan}

Perkembangan tenknologi dalam beberapa tahun terakhir telah membawa berbagai perubahan dalam berbagai aspek dari kehidupan masyarakat Indonesia tidak terkecuali aspek interaksi dan hubungan sosial. Terlihat dari data yang dipublikasikan oleh Kementerian Komunikasi dan Informatika (Kemenkominfo) pada tahun 2013, jumlah pengguna internet di indonesia terdapat 63 juta jiwa dengan 95\% dari angka tersebut memanfaatkan akses internet untuk jejaring sosial. Hal tersebut menunjukkan bahwa pemerintah Indonesia dapat dengan mudah menyampaikan informasi kepada masyarakat. Tentunya dengan angka pengguna internet di Indonesia yang cukup tinggi maka informasi dari pemerintah akan lebih mudah disampaikan melalui media sosial, terutama disaat pandemi Covid-19 yang membatasi masyarakat untuk melakukan kegiatan di luar rumah dan mengharuskan masyarakat untuk melakukan kegiatannya dari rumah.

Berdasarkan Kamus Istilah Periklanan Indonesia, Iklan Layanan Masyarakat ialah jenis iklan yang dikeluarkan oleh suatu organisasi, lembaga komersil, Lembaga nonkomersil atau pemerintah guna mencapai berbagai tujuan sosial, sosio-ekonomis serta meningatkan kesejahteraan masyarakat (Rudianto, 2018). Iklan layanan masyarakat yang dibuat dan ditampilkan dikanal Youtube Direktorat Promosi Kesehatan dan Pemberdayaan Masyarakat Kementrian Kesehatan Republik Indonesia berjudul 'Iklan Layanan Masyarakat Adaptasi Kebiasaan Baru Cegah Covid-19 di Fasilitas Olahraga' hingga saat ini telah ditonton lebih dari 20 ribu penonton.

Maka perlu dilakukan pengkajian efektivitas iklan layanan masyarakat yang dibuat oleh dan di tayangkan oleh kemenkes indonesia di Youtube dapat di uji menggunakan beberapa metode dan model dengan pertimbangan konsumen hidup dalam lingkungan yang kompleks yang mengarah pada kompleksitas perilaku mereka penggunaan suatu model penelitian efektifitas iklan menyederhana kan penjelasan dari perilaku penonton atau konsumen yang rumit atau kompleks tersebut. Maka dalam pengukuran efektivitas dalam penelitian ini akan digunakan EPIC Model yang dapat memisahkan 4 dimensi kritis sebuah iklan yaitu Empathy atau Empati, Persuation atau Persuasi, Impact atau Dampak, serta Communication atau Komunikasi. kemudian hasil dari pengukuran akan dianalisa dengan tujuan untuk mengetahui efektifitas seluruh dimensi EPIC tersebut secara terpisah sehingga dapat diketahui dari keempat dimensi, dimensi manakah dari yang terdapat kekurangan dan kelebihan demi mencapai tujuannya, agar selanjutnya dapat dibuat strategi baru untuk memperbaikinya.

\section{Metode Penelitian}

Penelitian ini akan memakai metode survey deskriptif, yang merupakan salah satu metode penelitan dengan mengambil sampel dari dalam suatu populasi kemudian memggunakan kuesioner sebagai alat untuk mengumpulkan data, yang selanjutnya data akan diamati untuk mencari kejadian-kejadian distributif, relatif, , secara sosiologis maupun psikologis. Riset ini mempunyai inti untuk mengamati perilaku yang sedang terjadi dan terdiri dari satu variabel atau univariat (Kriyantono, 2006). Populasi dalam penelitian ini adalah pengguna internet yang berdomisili dipulau Jawa, menggunakan media sosial Youtube dengan rentang umur 15 tahun keatas. Sampelnya adalah pengguna youtube yang berdomisili di pulau jawa berusia 15 tahun keatas 
penonton video 'Adaptasi Kebiasaan Baru Cegah Covid-19 di Fasilitas Olahraga' dalam Youtube.

Teknik pengumpulan data dalam penelitian ini menggunakan metode survey dengan cara penyebarkan angket atau kuisioner dengan skala likert. Kemudian data akan diuji keabsahannya dengan uji validitas dan reabilitas. Untuk proses pengolahan data dan analisis data penguji menggunakan Teknik tabulasi sederhana, dan juga skor rata-rata untuk mengetahui EPIC rate.

Tabel 1. Operasionalisasi Konsep

\begin{tabular}{|c|c|c|c|c|}
\hline Variabel & Konsep variabel & $\begin{array}{l}\text { Konsep } \\
\text { operasional }\end{array}$ & Indikator & $\begin{array}{l}\text { Skala } \\
\text { ukur }\end{array}$ \\
\hline $\begin{array}{l}\text { Efektivitas } \\
\text { iklan layanan } \\
\text { masyarakat } \\
\text { (X1) }\end{array}$ & $\begin{array}{lr}\text { Menurut } & \text { Cannon, et. } \\
\text { al, (2009) efektivitas } \\
\text { bergantung pada } \\
\text { sebaikapa medium } \\
\text { tersebut } \\
\text { dengan sesuai } \\
\text { strategi pemasaran } \\
\text { yaitu, padatujuan } \\
\text { promosi, pasar target } \\
\text { yang ingin dijangkau, } \\
\text { dana } \\
\text { tersediauntuk yang } \\
\text { pengiklanan, serta } \\
\text { sifat dari media, }\end{array}$ & $\begin{array}{l}\text { Pola } \\
\text { kehidupan } \\
\text { masyarakat } \\
\text { sehari hari }\end{array}$ & $\begin{array}{l}\text { Empati : } \\
\text { - } \quad \text { Afeksi } \\
\text { Persuasi : } \\
\text { - } \quad \text { Keinginan } \\
\text { berperilaku } \\
\text { Impact } \\
\text { - } \quad \text { Pengetahuan } \\
\text { produk } \\
\text { Communication } \\
\text { - } \quad \text { Kemampuan } \\
\quad \text { mengingat pesan }\end{array}$ & likert \\
\hline
\end{tabular}

Sumber: Dokumentasi Pribadi

\section{Hasil Temuan dan Diskusi}

Angket atau kuisioner akan dibuat dan disebarkan melalui google form setelah peneliti mendapatkan indikator. Kemudian akan dilalukan uji validitas dan validitas terhadap data yang telah dikumpulkan.

Tabel 2. Hasil Uji Validitas

\begin{tabular}{lllll}
\hline Pertanyaan & \multicolumn{1}{c}{$\boldsymbol{r}_{\text {hitung }}$} & \multicolumn{1}{c}{$\boldsymbol{r}_{\text {tabel }}$} & \multicolumn{1}{c}{ Kondisi } & kesimpulan \\
\hline Pertanyaan E1 & 0,885 & 0,361 & $r_{\text {hitung }}>r_{\text {tabel }}$ & Valid \\
\hline Pertanyaan E2 & 0,878 & 0,0361 & $r_{\text {hitung }}>r_{\text {tabel }}$ & Valid \\
\hline Pertanyaan P1 & 0,893 & 0,361 & $r_{\text {hitung }}>r_{\text {tabel }}$ & Valid \\
\hline Pertanyaan P2 & 0,906 & 0,361 & $r_{\text {hitung }}>r_{\text {tabel }}$ & Valid \\
\hline Pertanyaan I1 & 0,909 & 0,361 & $r_{\text {hitung }}>r_{\text {tabel }}$ & Valid \\
\hline Pertanyaan I2 & 0,802 & 0,361 & $r_{\text {hitung }}>r_{\text {tabel }}$ & Valid \\
\hline Pertanyaan C1 & 0,896 & 0,361 & $r_{\text {hitung }}>r_{\text {tabel }}$ & Valid \\
\hline Pertanyaan C2 & 0,913 & 0,361 & $r_{\text {hitung }}>r_{\text {tabel }}$ & Valid \\
\hline
\end{tabular}

Sumber: Hasil Olah Data Peneliti

Berdasarkan tabel 2 hasil uji validitas seluruh dimensi EPIC tentang efektivitas dari iklan layanan masyarakat 'Adaptasi Kebiasaan Baru Cegah Covid-19 di Fasilitas Olahraga' dinyatakan valid karena $r_{\text {hitung }}>r_{\text {tabel }}$. 


\section{Uji Reliabilitas}

Langkah berikutnya adalah melakukan uji reabilitas dengan tujuan untuk mengetahui tingkat reabilitas data tersebut.

Tabel 3. Hasil Uji Reliabilitas
Variabel
Koefisien Alpha
Koefisien $r$
Simpulan

Cronbach

\begin{tabular}{llll}
\hline Empathy & 0,713 & $0,600-0,799$ & Tinggi \\
\hline Persuasion & 0,764 & $0,600-0,799$ & Tinggi \\
\hline Impact & 0,621 & $0,600-0,799$ & Tinggi \\
\hline Communication & 0,777 & $0,600-0,799$ & Tinggi
\end{tabular}

Sumber: Hasil Olah Data Peneliti

\section{Hasil Skor Rata-rata}

Setelah dilakukan uji validitas reliabilitas kemudian data kuisioner akan ditabulasi dan di hitung skor rata ratanya untuk mendapatkan hasil dari EPIC ratenya.

Tabel 4. Skor Rata-rata Empathy

\begin{tabular}{llllll} 
& $\mathrm{N}$ & \multicolumn{2}{l}{ Minimum } & Maximum Mean & Std. Deviation \\
\hline E1 & 100 & 2 & 5 & 3.99 & .759 \\
\hline E2 & 100 & 2 & 5 & 4.01 & .718 \\
\hline Valid N (listwise) & 100 & & & &
\end{tabular}

Sumber: Hasil Olah Data Peneliti

Terlihat pada Tabel 4 menunjukkan hasil dari perhitungan skor rata-rata yang diperoleh dari kedua item dimensi Empathy adalah E1 sebesar 3,99 dan E2 sebesar 4.01

\section{Jumlah skor rata-rata dimensi Empathy}

$$
\begin{aligned}
& X(\text { Empathy })=\frac{3,99+4,01}{2} \\
& =4
\end{aligned}
$$

Maka hasil dari kumulatif rata - rata dimensi Empathy adalah 4.Sehingga posisi epic rate Empathy adalah:

\section{Gambar 1. Epic Rate Emphaty}

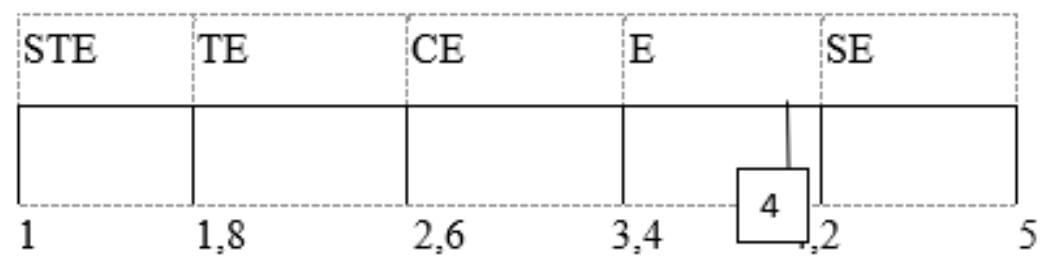

Sumber: Hasil Olah Data Peneliti

Dimensi Empathy masuk kedalam kategori efektif $(3,40$ - 4,20) jika dilihat menggunakan EPIC rate. Hal ini menginformasikan bahwa penonton menganggap 
iklan "Adaptasi Kebiasaan Baru Cegah Covid-19 di Fasilitas Olahraga" Dalam Media Youtube baik dan menarik.

Tabel 5. Skor Rata-rata Persuasion Descriptive Statistics

Std.

\begin{tabular}{lrrrrr} 
& N & Minimum & Maximum & Mean & Deviation \\
\hline P1 & 100 & 2 & 5 & 3.90 & .847 \\
\hline P2 & 100 & 2 & 5 & 4.06 & .886 \\
\hline Valid N (listwise) & 100 & & & &
\end{tabular}

Sumber: Hasil Olah Data Peneliti

Hasil perhitungan diatas menunjukkan skor rata-rata yang diperoleh dari kedua item dimensi Persuasion adalah P1 sebesar 3,90 dan P2 sebesar 4.06

\section{Jumlah skor rata-rata dimensi Persuasion}

$$
\begin{gathered}
X(\text { Persuasion })=\frac{3,90+4,06}{2} \\
=3,98
\end{gathered}
$$

Maka hasil dari kumulatif rata - rata dimensi Persuasion adalah 3,98.Sehingga posisi epic rate Persuasion adalah:

Gambar 2. Epic Rate Persuasion

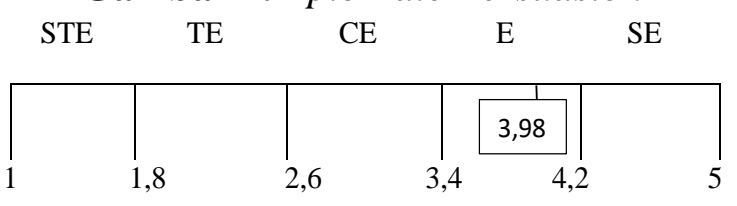

Sumber: Hasil Olah Data Peneliti

Dimensi Persuasion masuk kedalam kategori efektif $(3,40-4,20)$ jika dilihat menggunakan EPIC rate. Hal ini menginformasikan bahwa penonton iklan layanan masyarakat "Adaptasi Kebiasaan Baru Cegah Covid-19 di Fasilitas Olahraga” Dalam Media Youtube memberikan keyakinan pada masyarakat untuk mengikuti anjuran dari pemerintah dalam iklan layanan masyarakat tersebut.

Tabel 6. Skor Rata-rata Impact Descriptive Statistics

\begin{tabular}{lrrrrr}
\hline & & & & Std. \\
& $N$ & Minimum & Maximum & Mean & Deviation \\
\hline I1 & 100 & 1 & 5 & 3.79 & .891 \\
\hline I2 & 100 & 2 & 5 & 3.98 & .804 \\
\hline Valid N (listwise) & 100 & & & & \\
Sumber: Hasil Olah Data Peneliti & & & &
\end{tabular}

Hasil perhitungan diatas menunjukkan skor rata-rata yang diperoleh dari kedua item dimensi dimensi Impact adalah I1 sebesar 3,79 dan I2 sebesar 3,98. 


\section{Jumlah skor rata-rata dimensi Impact}

$$
\begin{aligned}
X(\text { Impact }) & =\frac{3,79+3,98}{2} \\
& =3,88
\end{aligned}
$$

Maka hasil dari kumulatif rata - rata dimensi Impact adalah 3,88. Sehingga

\begin{tabular}{|c|c|c|c|c|}
\hline \multicolumn{5}{|c|}{ Gambar 3. Epic Rate Impact } \\
\hline STE & TE & $\mathrm{CE}$ & $\mathrm{E}$ & SE \\
\hline & & & 3,88 & \\
\hline & & & & \\
\hline
\end{tabular}
posisi epic rate Imapct adalah:

Sumber: Hasil Olah Data Peneliti

Dimensi Impact masuk kedalam kategori efektif $(3,40-4,20)$ jika dilihat menggunakan EPIC rate. Hal ini menginformasikan bahwa penonton mendapatkan informasi lebih setelah menonton iklan "Adaptasi Kebiasaan Baru Cegah Covid-19 di Fasilitas Olahraga” Dalam Media Youtube.

Tabel 7. Skor Rata-rata Communication

\section{Descriptive Statistics}

\begin{tabular}{lcrrrr}
\hline & & & & \multicolumn{2}{c}{$\begin{array}{c}\text { Std. } \\
\end{array}$} \\
& $\mathrm{N}$ & Minimum & Maximum & Mean & Deviation \\
\hline $\mathrm{C} 1$ & 100 & 2 & 5 & 4.17 & .753 \\
\hline $\mathrm{C} 2$ & 100 & 2 & 5 & 4.16 & .721 \\
\hline Valid N (listwise) & 100 & & & & \\
& Sumber: Data primer diolah pada tahun 2021 &
\end{tabular}

Hasil perhitungan diatas menunjukkan skor rata-rata yang diperoleh dari kedua item dimensi Communication adalah $\mathrm{C} 1$ sebesar 4,17 dan C2 sebesar 4.16

\section{Jumlah skor rata-rata dimensi Communication}

$$
\begin{gathered}
X(\text { Communication })=\frac{4,17+4,16}{2} \\
=4,16
\end{gathered}
$$

\begin{tabular}{|c|c|c|c|c|}
\hline STE & TE & $\mathrm{CE}$ & E & SE \\
\hline & & & 4,16 & \\
\hline & & & 4, & \\
\hline
\end{tabular}

Maka hasil dari kumulatif rata - rata dimensi Communication adalah 3,88. Sehingga posisi epic rate Communication adalah:

Gambar 4. Epic Rate Communication

Sumber: Hasil Olah Data Peneliti

Dimensi Communication masuk kedalam kategori efektif $(3,40-4,20)$ jika dilihat menggunakan EPIC rate. Hal ini menginformasikan bahwa penonton mengerti 
isi pesan dari iklan "Adaptasi Kebiasaan Baru Cegah Covid-19 di Fasilitas Olahraga" Dalam Media Youtube.

\section{Hasil Analisis EPIC Model}

Gambar 5. Grafik EPIC Model

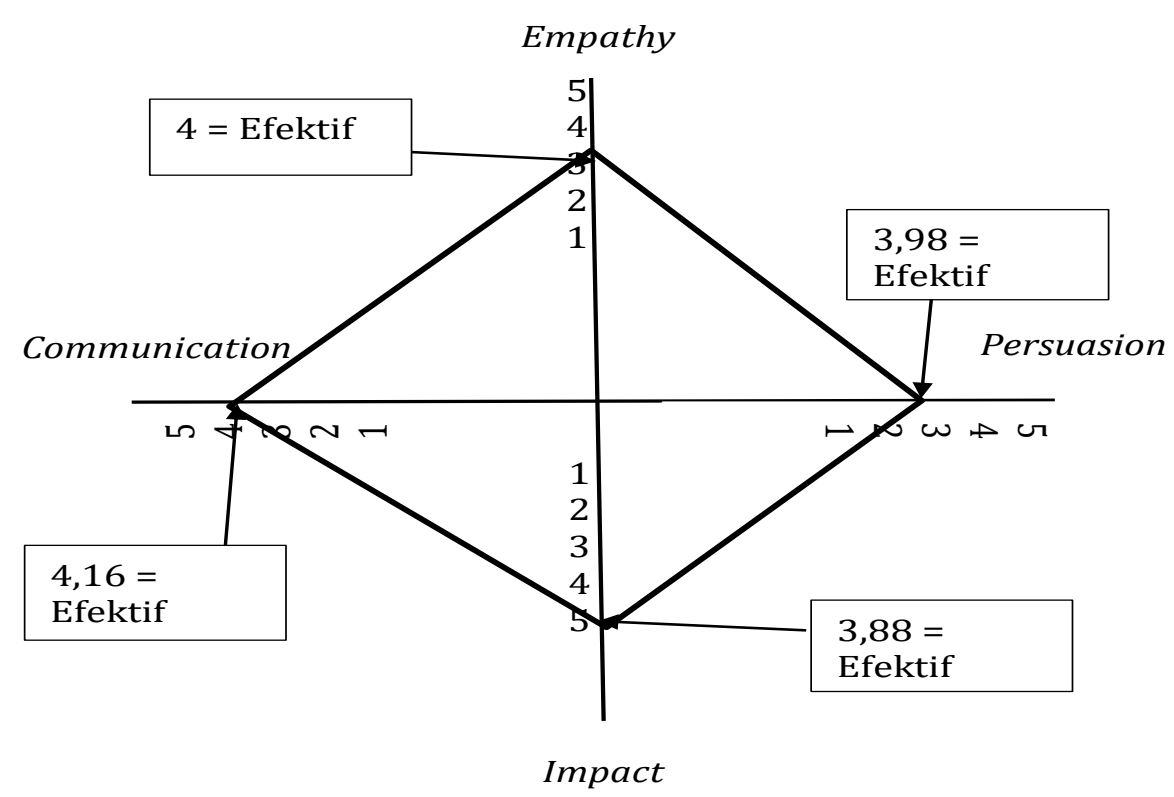

Sumber: Dokumentasi Peneliti

Dilihat dari grafik diatas dapat diketahui bahwa dimensi Communication merupakan dimensi yang paling menonjol pada iklan layanan masyarakat "Adaptasi Kebiasaan Baru Cegah Covid-19 di Fasilitas Olahraga" dibandingkan dengan tiga dimensi lainnya. Dengan angka EPIC rate yang tinggi artinya dimensi Communication mempunyai dampak yang paling efektif untuk mengenalkan dan mengarahkan penonton untuk melkukan himbauan dari pemerintah.

\section{Simpulan}

Kesimpulan yang didapatkan setelah melalui proses pengolahan ,analisis data, dan pembahasan maka hasil dari penelitian tentang efektivitas iklan layanan masyarakat 'adaptasi kebiasaan baru cegah covid-19 di fasilitas olahraga' dalam media youtube jika diukur menggunakan EPIC Model hasilnya adalah seluruh dimensi EPIC Modelnya Efektif. Dan dimensi yang paling efektif jika dibandingkan dimensi lainnya dalam iklan layanan masyarakat tersebut adalah Dimensi Communication atau komunikasi. Hal ini menunjukan bahwa item pernyataan "Iklan Layanan Masyarakat 'Adaptasi Kebiasaan Baru Cegah Covid-19 di Fasilitas Olahraga' di Youtube mengarahkan saya untuk menaati protokol kesehatan" didominasi penonton yang menjawab setuju, dan tergolong dalam kategori efektif. Secara keseluruhan iklan layanan masyarakat 'Adaptasi Kebiasaan Baru Cegah Covid-19 di Fasilitas Olahraga' di Youtube merupakan iklan yang efektif jika dilihat dari keempat dimensi EPIC. 


\section{Ucapan Terima Kasih}

Peneliti ingin mengucapkan terima kasih kepada Fakultas Ilmu Komunikasi Universitas Tarumanagara, narasumber, serta semua pihak yang turut membantu peneliti sehingga penelitian ini dapat diselesaikan.

\section{Daftar Pustaka}

Kemenkominfo. (2013). 29 Agustus 2021.Pengguna internet di Indonesia 63 juta orang. https://kominfo.go.id/index.php/content/detail/3415/kominfo+\%3A+penggun a+internet+di+indonesia+63+juta+orang/0/berita_satker

Pujianto. (2013). Iklan Layanan Masyarakat. Yogyakarta: Penerbit Andi.

Rudianto, Bayu Aji, B., Aulia Nurdini, R., \& Fadilah. (2018). Perancangan animasi multimedia iklan layanan masyarakat tentang proses pembuatan e-ktp. 3(1), 31-38.

Sari, Melizza Purnama. 2012. Efektivitas Iklan Layanan Masyarakat di Televisi dalam Mempengaruhi Sikap Khalayak (Studi pada Mahasiswa FISIP Universitas Indonesia Depok Terhadap Iklan Layanan Masyarakat BKKBN Versi “Jangan Buru-Buru”). Skripsi Ilmu Komunikasi. Depok: Universitas Indonesia.

Sugiyono (2011). Metode Penelitian Kuantitatif, Kualitatif dan R\&D. Bandung: Afabeta. 